\title{
SOCIAL PROGRAMMING AS AN ALTERNATIVE IN FRONT OF SMALL BUSINESS OR SMALL BUSINESS A CHALLENGE TO SOCIAL PROGRAMMING
}

\author{
Venelin Terziev $^{1 *}$, Dimitar Kanev ${ }^{2}$, Veselin Madanski ${ }^{3}$ \\ ${ }^{1}$ Corresponding Member of the Russian Academy of Natural History, Moscow, Russia, Professor, \\ Ph.D., D.Sc. (National Security), D.Sc. (Ec.), University of Rousse, Rousse, Bulgaria; National \\ Military University, Veliko Tarnovo, Bulgaria; University of Telecommunications and Post, Sofia, \\ Bulgaria, terziev@skmat.com \\ ${ }^{2}$ Professor, Ph.D., D.Sc. (Ec.), Naval Academy, Varna, Bulgaria, kanev@dkanev.com \\ ${ }^{3}$ Colonel Associate Professor, Ph.D., D.Sc. (National Security), National Military University, Veliko \\ Tarnovo, Bulgaria, madansky@yahoo.com \\ ${ }^{*}$ Corresponding author
}

\begin{abstract}
The exhibition is related to the review and analysis for the last years of the development of two vital ideas for the Bulgarian society - small business and social programming. The increasing capacity of social programming and the proven viability of small businesses create conditions, even in crisis situations, for successful ideas to generate many tangible and intangible goods that society needs for its existence and perfection. The symbiosis of these two socio-economic phenomena forms the conditions in which a number of initiatives find way for realization. Indeed, in the established economic situation, a number of sectors continue to exist precisely through the presence of small business entities who successfully and actively participate in the implementation of social programs and declare their expectations for the structuring of program frameworks.
\end{abstract}

Keywords: small business; social program; social adaptation.

\section{MAIN TEXT}

It has been written enough for the small business, and at the same time insufficient. The reason for this claim is rooted in its ability to appear wherever there is a certain shortage in production and goods and services provoked by the closing of certain old factories and enterprises. It is in such conditions that the creative beginnings and entrepreneurial spirit are manifested.

The analysis of the „small business” phenomenon is a process in which the vast amount of literature studied 
and the exhaustive retrospection cannot accurately account for the occurrence and emergence at a particular point in the evolution of conscious human activity. It is certain that the review of all directions and areas in which this socio-economic phenomenon emerges and develops proves that its path is sufficiently long and the beginning lies in antiquity (Maymeskulov, 2014 c. 82). It is not so important whether the need to preserve any specific professional skills and habits in the family or the possibility of ensuring the existence of certain small personality formation is the root cause or the occasion. What is important is that, although limited and small, both as a definition and capacity, this type of conscious and purposeful human expression has left very profound marks of the process of development and improvement affecting the past and present of the human race.

Summarized data from the recent years prove that worldwide the small business accounts for more than $70 \%$ both for work organization and for presence. Although there are rather contradictory opinions on these facts, it is considered that in Bulgaria the share of small business accounts for about $90-93 \%$. In the structure of this impressive share, the only variable is the exact ratio of micro-enterprises - small enterprises under the meaning of the Bulgarian legislation. This written so far has formed the impression that the "small business" generic category has an increasingly tangible presence in modern economic life (Stoyanov, 2014, p. 9). Various manifestations create some difficulty for a full and comprehensive definition. In this context, it may be more appropriate to analyse the key features that define this phenomenon and specify it.

The analysis of small business gives reason to believe that its essence relies on the entrepreneurial spirit and the development of project thinking. This conceptual-ideological symbiosis provides evidence that it is too difficult and risky to indicate what and under what conditions is differentiated as a cause and what as a consequence.

Still, in chronology, entrepreneurship as a phenomenon has attracted the attention of a number of scholar economists long time ago, i.e. long before the appearance of the concept of the projects and the changed thinking related them. In addition, the theoretical developments looking at entrepreneurship a little earlier create the conditions to consider that in the economic stagnation of the $1970^{\mathrm{s}}$ the so-called "entrepreneurial revolution" is a chance or an alternative for the economic development. This idea finds followers in the transformations that took place in the economies of the post-socialist economies in the early 1990s.

Generally, it can be said that in the fundamental classical studies of economic theory (Smith, Say, Mill, etc.) and in the contemporary ones there is no unambiguous definition of the socio-economic phenomenon of entrepreneurship.

Explanation of this may be sought in several ways:

First, economists focus their attention on the big business (Brock, Evans, 1989, p. 7).

Second, the development of models and theories built on exact science (Bygrave, Hofer, 1991, pp. 12-14).

Third, multi-directional searches in optimizing government regulation.

Indeed, if qualifiers and definitions of entrepreneurship have to be registered, perhaps the list will be very long, because the phenomenon has existed since the $17^{\text {th }}$ century (Andronov, Aleksandrova, 2003, p. 7). Opinion on this issue was provided, in addition to the quoted classical economists, also by Marshall, Knight, Schumpeter, Thünen, Mises, Hayek, Kirzner, Axe, Kahn, Sokoloff, and others.

The analysis of the various definitions proves that in each of them the focus of the point of view affects different essential characteristics of the phenomenon. The range is far too wide from the existence of unpredictable risk, according to Cantillon, to the formation of entrepreneurial income, focused by Say on the one hand, and on the other, the implementation of a particular type of personal behaviour commented by Schumpeter to the systematic investment in innovation, reflected by Kahn and Sokoloff (Andronov and Riskat, 1985, p. 17).

However, by summarizing a dozen definitions, it can be argued that entrepreneurial activity is a process of establishing an organization with a commercial purpose, which uses in its activity specific operations and certain resources at high risk to achieve fixed results (Draft, 2005 p. 214).

The other conviction that emerges from the critical review of entrepreneurial perceptions is that it can predominantly be almost identical to the attempts to discover features that acquire definitions of the small business. In other words, in most cases, a small business engine is the entrepreneurial spirit of the entrepreneur who implements his ideas in a high-risk market environment (Davidkov, 1993), taking into account a number of legal and moral constraints and hierarchical dependencies.

The other concept, which is consolidated with the entrepreneurial concept and influences the development of 
the idea of a small business, is the entrance of the projects into the contemporary economic reality. Although being a much more recent one, the concept of projects and the development of project thinking generate a very serious economic effect, due to which the last years of the twentieth century can boldly be recognized as a „project revolution”.

Attempts to define the term "project" register two approaches to determining its nature. One treats it as a cumulative process associated with a specific result, and the other as a set of logically arranged activities planned for a specific duration and purpose.

Looking at small businesses as a specific form of socio-economic existence and development, it may be more appropriate to attach to it the first approach. In this sense, despite the many definitions, it is more appropriate to assume that "the project is a separate enterprise with defined objectives, often including requirements related to duration, value and quality of the desired results" (APM, 1992, p. 4).

The minimal incompatibility between the nature of the project and that of small business is the uncertainty in the definition related to the use of time resource. But here too, the interpretation can be seen in two ways, because each project is based on a limited time and budget, while the small business may not work in unlimited time, but in most cases with resource constraints. In this context, it is appropriate to define that the project is an "entrepreneurial effort organizing human, financial and material resources in a certain way within a unique set of tasks with a specified specification, with limited costs and time, and by implementing the lifecycle of the project successful changes are made defined by quantitative and qualitative goals and tasks" (ICB-IPMA, 1999).

The short but critical analysis of the essence of the "small business" phenomenon does not claim to be comprehensive but reveals the mechanism that makes it sustainable and highly adaptable in today's economic conditions and at the same time enables it sell the goods and services produced, to mediate and consult, i.e. to be where the bigger ones have no interest or opportunity. (Davidkov, 1998). In the operation of small business it is quite natural to take into account the influence of the intense changes in the economic environment provoking demand for change in different directions and at the most diverse levels of human knowledge. The variety of approaches, methods and overall methodologies are more generally focused on key processes such as management, and in detail on such as decision-making, organization building, and a number of others. The analysis of the environment in which small businesses exist provides evidence that there are several significant trends such as: narrowing of markets despite globalization, the growth of the service sector due to the growing needs, escalating competition, the difficulty in finding high tech solutions to increase productivity and more. Their presence and importance form the question whether the challenge of risk or creativity is leading in modern management (Davidov, Andronov, 1983, p. 31).

The commented economic conditions, and especially the tendentiously developing basic characteristics, create prerequisites for a kind of renaissance of interest in a specific functional field of socio-economic management, as is the operational management. The focus on this area of human knowledge is adequate and appropriate as some features of small businesses (scale, specifics of activity, capacity, etc.). As in other areas of science and research a number of researchers present their views by concentrating them on definitions and structuring them in scientific studies. The starting point is the understanding of an operation that is interpreted as a „process, method or set of actions of predominantly practical nature” (Colins, 1986). In this context, „operations are an integral attribute of every conscious human activity, which inherently needs to be organized and productive" (Galloway, 1994, p. 6).

Based on the perceptions of the essence of the economic notion of "operation", many authors create definitions for operational management. However, the scope of the interpretation is not broad, but on the other hand the emphasis is placed on the fact that the operational management encompasses the decisionmaking process (Andronov, 1983, p. 188) for an appropriately directed "transformation of the materials into a finished product and its delivery to the user" (Galloway, 1994, p. 11).

The structure of the process that is the object of the operational management contains several key components - the decision-making act and the resulting responsibility, the process of transformation of materials, energy, labour, capital and information and the act of product sale. Analysis of the component content of the process confirms that it is the operations that convert the materials into products and services but they also generate "another result" measured by heterogeneous types of responsibility in terms of change of result, effective capacity, convenient availability, sufficient human capital and optimal quality.

It has been shown that the interaction of economic reality and organization predetermines processes of mutual influence in both directions. It is normal to think over the changes that have occurred, as well as to clarify that an internal organizational and external environment for the organization are defined. Practice convinces that it is precisely a deviation that reveals something different, suggests innovation or points to a 
model of a true solution. It is not accidental that new models often appear as good attempts at improvement in the different stages of socio-economic development.

As such, specifically for functional improvement, the model known as the "Shewhart/ Deming Cycle" (Deming, 1950, p. 58) is perceived. This model is itself a process related to product, service or process analysis and optimization (Deming, 2006, p. 69). Its structure distinguishes four stages: planning, experimental actions, analysis and introduction of change. Objectively, each stage has a fixed, but also a creative nature. The reason for its inclusion in the essence and specificity of small business is that on the one hand, specific operations can be taken into account in the content of each stage, i.e. there is a possibility of upgrading and in the testing of the next result a solution can be identified for the initiation of a new operation and, on the other hand, the object of optimization are mostly the results of the normal activity of small business materialized mainly in the form of goods and services.

In conceptual terms, the structure in the mid $-1980^{\mathrm{s}}$ is considered and perceived as a material expression of the organization only if it meets two key conditions - to divide the core activity of specific operations while coordinating the actions of their implementation. In this line of thought, a specific structural configuration is interpreted as a fixed response in coordinating certain operations, or in other words, architectural design is an active form of coordination, and most importantly, a specific control format, set on the system of operations.

The above written lines on the small business phenomenon provide an opportunity to conclude that this is a phenomenon that has acquired the characteristics of an economic phenomenon due to its characteristics high resilience and incredible adaptability. Together with the opportunity to engage in diverse and almost impossible business combinations, it proves that it can be likened to a compensatory mechanism of the existing economic systems, covering a deficiency in almost all economic areas and areas. The consolidation of the entrepreneurial spirit and the markedly practical thinking make it a significant socially-based institution, which, together with its sustainable present, accumulates a potential for a guaranteed future.

Still, given that change is the only constant in social processes for the realization of a better future, it is appropriate to envisage certain trends that society initiates, imposes and adopts in order to make its wellfounded expectations into reality. In this sense, since the late 1980s, the focus of attention has been shifted from optimizing the quality of the operations to the implementation of various scale strategies. As an essential proof of this process is the perception and development of the idea of a strategically oriented organization. At organizational level, these are usually successful organizations, and at the aboveorganizational level these are the economically more stable countries materializing the concept through the transformation of structured programs and doctrines into concrete actions and policies.

At the heart of the analysed tendency in state and social development are principles of strategic management. In a modern economic sense, the strategy is characterized as a set of theories that form a certain management doctrine, with the development of tactical descriptive plans (Trifonova, 2005,). The variety of adequate definitions of the concept under consideration does not obstruct the process of improving its content, but at the same time it tracks the evolutionary development of the idea on the basis of which it is formed.

In the 1960s, the idea was that the strategy was to define the organization's main long-term goals and tasks and to take action, allocate resources to meet these goals (Chandler, 1965, p. 13). It is developed in the context of the Theory of the Decision, linked to the achievement of objectives by choosing a combination of available resources.

The next stage in development is related to representatives of the Game Theory (Coates, 1978, p. 143), according to whom the strategy is a specific use of resource availability under the control of the decision subject, whose preference is to choose one of the available strategies (Miller, 1967, p. 157). At this stage of the development of the management thought, Bulgarian authors also emphasize the use of the material and labour resources as a major factor for the implementation of the organizational strategy. An important aspect of the economic strategy is the introduction of the requirement to study the behaviour of corporate counterparts and competitors in the light of defined and implemented initiatives for the strategic development of organizations (Dinev, 1985, p. 200).

In the 1970s the strategic management concept unfolds a discussion on the role of strategic planning in order to clarify whether it is content or is one of the components of strategic management. The substantial transformation that has been registered at this stage in the content of "corporate planning" is shaped by the emphasis placed on its long-term nature, given its strategic aspect, in order to be conceptualized as an essential part of strategic management. At this stage, corporate planning records the need for a rational plan covering all aspects of economic activity (Trifonov, 2005). At the same time, strategic planning addresses the 
plan by focusing on its long-term and targeted nature (including the financial plan but excluding its detailed short-term alternative in the form of accounting budgeting). Strategic management focuses on the overall structural reorganization of organizational activity with the intention of adapting it optimally to changes in the environment.

In the development of strategic management in the late $1970^{\mathrm{s}}$, Ansoff's theoretical developments were particularly influential. Following the logic of the thesis that strategic decisions relate mainly to external rather than internal problems of the organization and especially to the choice of production nomenclature and the markets for its realization, he continues and develops it further (Ansoff, 1965, p.9). Considering each solution as a resultant variable concretized under the influence of incoming information from the outside environment, in the form of signals of varying intensity and significance, Ansoff and his school develop a "Method for the Use of Weak Signals" (Ansoff, 1984, pp. 430-471).

In the analysis of the proposed methodology, the factor value of the input information is raised. The accent is emphasized on weak signals from the external environment as the most important source to indicate emerging trends that predetermine the planning of responses by the organization in question. Response dynamics and a wide choice of decision options diagnose readiness and provoke successful strategic development in the conditions of weak signals.

In the process of exhibiting the theoretical development of Ansoff, along with the proven innovations that give drive to the ones seeking motives for improvement in the development of the strategic topic, some weaknesses can be noted. First of all, the implementation of control in strategy modelling is ignored. It is formed as a result of the impact of weak signals from the external environment. The role of the control is diminished, it is formalized and applies only to incoming information. The deformation found of the control function is deficient both in the implementation of the strategic process and in the mechanism of its updating.

In the $1980^{\text {s }}$, the strategic management concept based on the strategic analysis thesis gradually emerged. Management theory specialists at this stage broaden the scope of strategic analysis to include all aspects of organizational environmental relations. This determines a far greater variety of management objects that can be categorized and qualified as the subject of strategic research.

The characteristics of the economic strategy are objectified by fixing its target content, focusing on the role of the production-financial factors, emphasizing the necessity to acquire competitive advantages of the organization. The strategy at this stage is considered as a basic framework for cost-effective, resourceefficient utilization by specifying the procedures for realization of organizational, business goals (Hofer, 1978, p. 25). The opinion is formulated that the strategy ensures the possibility of achieving a competitive advantage (Porter, 1985, p. 26). The formulated strategic decisions are differentiated from the perspective of the specificity of the organization under consideration and its sectoral situation - factors that influence the applied methods used in the process of making the specific decisions.

The strategy has, above all, the characteristics of a specific expression of the particular organization, clearly defining it as a selective, forward-looking activity, sustainable over time, focusing on certain priorities (Mintzberg, 1997, pp. 23-45) and organizational characteristics. In its meaning, it is a long-term plan for permanent performance tracking of the use of the aggregate of internal and external resource potential in the hierarchical management structure to implement organizational goals. Formal and content requirements are formulated to differentiate the strategy so that it is clearly defined to qualify as a logical unity of management interpretations and solutions for specific objectives and specific policies for their implementation, established range of regulated activity and expected effects of its implementation (Andrews, 1980, p. 6).

An important role in the development of management thinking about strategic management has the Minzburg School. This school, in the full and specific sense, can be defined as alternative in terms of evolution in the development of strategy topic. In the course of time, the definitions of strategy in the economic sphere are specified in the preservation of its target character, but the focus of the material, resource factors shifts on the intangible ones, reinforcing their priority (Mintzberg, 1973a, p. 47). This qualitative jump registers a tendency for a change in the strategic process, with the corresponding conceptual weight of planning shifting to system analysis. In terms of content, the 'behavioural model' addition is also included to the definition of the strategy.

The combination in the process of making and implementing a strategy of several characteristics, such as an action plan, a pattern of behaviour, a means of achieving and retaining a competitive position, proves in addition not only content but formal improvement either (Mintzberg, 1973b, p. 47). Emphasizing the process of modelling and implementing a specific behavioural model and introducing adjustments to it in order to fully coordinate between the potential of the behavioural model and the desired strategic outcome proves the irreversibility of the process of introducing the Feedback Mechanism into the strategic process. 
Strengthening the role of feedback in the strategic process traces the possibilities for development and improvement both in content and in functional terms.

By analysing the turbulent processes of dynamic economic reality, by comparing the significance of theoretical developments for the development of management thought, proving the increasing impact of their practical applicability, it can be assumed that Ansoff's main contribution is to focus attention on the issues of implementing a strategy, although this importance in some areas is over-exposed (Ansoff, 1984, pp. 33-36). As the most significant contribution of the Mutzberg School, one can note the motivated shortening of the implementation cycle of strategies and the introduction and demonstration of the growing role of strategic control with feedback (Mintzberg, 1979, pp. 34-43).

As a method of organizational management, the strategy was initially implemented in the field of organizational activity planning (Stoyanov, 2013, p. 141). In the period 1970-1990, strategic planning has become a leading avenue in theoretical and managerial thinking in the most advanced economies. Currently, strategic management is sufficiently detailed in the methodological management theory. It is seen as a unity of formulated, managerial decisions and actions taken in connection with the definition and implementation of strategies to achieve certain organizational goals, organized as a process through which long-term, sustainable development is implemented (Mihnev, 1999, p. 19). A certain group of Bulgarian authors engage the content of organizational, strategic management also with the inevitable inclusion of operational / situational / management based on the attachment of the organization to a specific strategy. Naturally, prioritizing the strategic management with the process of developing strategic and respectively long-term solutions (Pamukchiev, 2002, p. 189).

In recent years it was on this basis that the concept of social programming has developed (Terziev, 2015). In general, established and socially committed strategies turn into policies, and the set of policies structure the stated socio-political doctrines also known as "program frame works“.

The short analyses made proved that the specifics of the phenomena under consideration and their essential characteristic define them as factors of a system which in their interaction reveal trends of development and presence of problems (Terziev, 2013, pp. 54-57) The interaction process acquires a dynamic and continuous nature that brings variable success for many reasons, two of which are based on the state of small business and social programming:

The first is related to the active role of small business, interpreted as a subject that constantly experiments and seeks for success and change.

The second, in which social programming is perceived as a specific expression of the interests of society and the will of the state to create conditions in which economically active entities, including small businesses, can achieve stable and fruitful behaviour.

The above written lines of the expose predetermine the generalizing conclusion that small business is a mandatory requisite in the social system that materializes innovative ideas in many areas and shows high sustainability, including in a crisis. In this context, it is expressed as a test of new and unconventional ideas and a challenge to social programming. Finding a direct and adequate link between social programs and initiatives suggested by small businesses would create a more sustainable business environment and would in particular prove that the state not only thinks about the future of all the subjects who build its authority but creates doctrines and programs in which to consolidate their intentions, interests and efforts.

\section{REFERENCES LIST}

Chandler, A., (1965) Strategy and Structure, Cambridge, Mass: MIT Press.

Coates, C., (1978) Investment Strategy, McGraw-Hill.

Hofer, C., D., Schendel, (1978) Strategy Formulation: Analytical Concepts, NY.

Davidov D., E. Andronov, Hr. Dalkalachev, Dalkalchev, (1983) Risk and Creativity in the Management of the National Economy, S., New Time magazine, issue 12.

Miller D., M. Starr, (1967) The Structure of Human Decision, Prentice-Hall.

Stoyanov E.N., (2014) Small Business Organization, Analysis and Evaluation, Libra Scorpio, Bourgas.

Stoyanov E.N., (2013) Theory of Financial and Economic Analysis, Libra Scorp, Bourgas. 
IJASOS- International E-Journal of Advances in Social Sciences, Vol. III, Issue 9, December 2017

Andronov E., M. Aleksandrova, (2003) Decision Making in Risk Situation in Bulgarian Micro-Enterprises Factors, Problems, Prospects, Sofia.

Deming E., (1950) Elementary Principles of the Statistical Control of Quality, JUSE.

Deming E., (2006) The New Economics, 2-th ed, Cambridge, Mass: MIT Press.

Andronov E., (1985) The Risk and Its Reporting in the Business Decision Making Process, (thesis), S., UNWE.

Mihnev G., (1999) Strategic management of agricultural holdings, Holding, S.

Mintzberg, H., (1973a) Strategy-Making in Three Modes, California MR, Winter.

Mintzberg. H., (1973b) The Nature of Managerial Work, NY; Harper \& Row.

Mintzberg, H., (1979) The Structure of Organizations. Englewood Cliffs, NJ; Prentice-Hall.

Mintzberg, H.,B. Ahlstrand, J. Lampel, (1997) Strategy safari. A Guided Tour Throut the Wilds of Strategic Management.L.etc.

Ansoff I., (1965) Corporate Strategy, NY.

Ansoff I., (1984) Implanting Strategic Management, Prentice/Hall I.; N.J.

Ansoff, I., (1984) Implanting Strategic Management, Prentice/Hall I.; N.J.

Andrews,K., (1980) The Concept of Corporate Strategy, 2-nd ed., NY.

Galloway L., (1994) Principles of operations management, London, ITBP.

Maymeskulov L., (2014) Goddess and Right Ancient Peace, M., SPO.

Dinev M., (1985) Social Control and the Working Group, Profyzdate.

Porter M., (1985) Competitive,Strategy, Free Press, NY.

Pamukchiev M., (2002) Fundamentals of Management, ABC Technika, S.

Daft R. L., Vanderbilt University, Management, 6-th edition, Thomson, 2005.

Trifonova S., (2005) Strategies for Development of Electronic Financial Services in Bulgaria, UNWE Labor.

Trifonov T., (2005) Strategic Analysis as a Contemporary Prerequisite for Improving the Accounting Valuation Study, UNWE Labor / 2005.

Davidkov Tsv., (1993) New Entrepreneurs (Results of Empirical Sociological Research), S.

Davidkov Ts., (1998) Entrepreneurship and Small Business. Social roles and self-identification, S., Economics, vol.2.

Terziev, V., (2015) Stoyanov, E., Arabska E. Aktivnata The Active Social Agenda - an Innovation Model in Public Development. Youth Forum „Science, Technology, Innovation, Business - 2015“, Collection of Reports.

Terziev V., (2013) Impact of Labor Market Policies on Employment, Dema Press Rousse.

Brock W., D. Evans, (1989) Small business economics, SBE $\backslash 1$.

Bygrave W., C. Hofer, (1991) Theorizing about entrepreneurship, ETP \v.16, N II.

Body of knowledge, APM, UK, (1992)

ICB-IPMA Competence Baseline.Version 2.0., IPMA Editorial Committe. Bremen, Eigenverlag, 1999 .

Davidkov Ts., (1998) Entrepreneurship and Small Business. Social roles and self-identification, S., Economics, vol.2.

Collins English Dictionary, UK, London, (1986).

Andronov EEconomic (1983) Risk and the Process of Making Economic Decisions, Scientific Papers of the Higher Economic Institute „K.Marks“, Sofia. 